\title{
LITHELY ARCH BRIDGE: A REVIEW
}

\author{
R.V. Popate \\ Department of Civil Engg. \\ PJLCE, Nagpur, Maharashtra, India
}

\author{
Sheikh Md. Sabir \\ Department of Civil Engg. \\ PJLCE, Nagpur, Maharashtra, India
}

\author{
R.H. Mohankar \\ Department of Civil Engg. \\ PJLCE, Nagpur, Maharashtra, India
}

\begin{abstract}
The masonry arch is one of the oldest structural elements. Brick masonry arches have been used for hundreds of years. This technical note is an introduction to brick masonry arches. Many of the different types of brick masonry arches are discussed and a glossary of arch terms is provided. Material selection, proper construction methods, detailing and arch construction recommendations are discussed to ensure proper structural support, durability and weather resistance of the brick masonry arch. Lithely arch method is innovative, modern, economic and fastest method of construction of arch bridges. This method is invented in Maharashtra, India. Bridges constructed using this method are purely compressive in nature. This method utilizes precast units for construction of arch bridges. This method can be utilized for rehabilitation of old arch bridges in India very economically and with less time.
\end{abstract}

Keywords - Lithely Arch, Wire Rope, Sockets, Screed Concrete, Spandrel Wall, Plum Concrete

\section{INTRODUCTION}

Most of masonry arch bridges, not only in India but world over, are more than 80-100 years old. After advent of concrete, masonry arch bridges are no more being constructed. Contrary to doubts, masonry arch bridges are proving durable with life-cycle costs significantly more economical than for the majority of other type of structure. Masonry arch bridges are part of our heritage. To preserve our heritage and to utilize these bridges to their maximum capacity, understanding of arch bridges is vital. as no more masonry arch bridges are being constructed in modern times, engineers have forgotten the old thumb rule methods of their design and also there are no common software available which can analyses the arch bridges correctly taking into account effect of fill, spandrel walls etc. the design of these structures was based on empirical rules which were too conservative, this has resulted in structures with an inherent ability to withstand the applied loads and extreme weathering conditions. Masonry arch bridges form an integral part of the railway infrastructure. They are the oldest structure type of the railway bridge population with thousands still in service despite their age and the significant changes in loading conditions that have occurred since their construction. Today many masonry arches carry a load that is radically different from that when they were constructed.
The condition of masonry arch bridges can vary from good to very poor, but nevertheless they have proven durability with life-cycle costs significantly lower than the majority of other structure types. Total replacement of deteriorated masonry bridges is generally unnecessary and is also expensive and therefore maintenance strategies should promote solutions that preserve and restore arch structures. In order that the railways may accommodate increased axle loads, train speeds and a greater volume of freight traffic, it is necessary to assess the load carrying capacity of existing masonry arch bridges. Assessment of masonry arch bridges is fraught with difficulties as there is little knowledge or experience of the design of arch structures to modern standards, and such structures may have parts hidden from view. The hidden parts, however, influence the structural behavior and have a major effect on the load carrying capacity of these bridges. To provide confidence in the assessment result, reliable input parameters are required. Accordingly effective inspection and measuring methods to establish the parameters are necessary. In addition to visual inspections, there has been a tendency in recent years towards the use of non-destructive testing techniques and destructive investigation to establish the necessary dimensional and material parameters.

The lithely arch is India's only precast, unreinforced bridge solution and is developed on the lines of the conventional stone-mason built arch bridges.0arch bridges are the most reliable and time tested solution for medium span $(5 \mathrm{~m}$ to $20 \mathrm{~m}$ ) bridges. These bridges have been standing strong for centuries and while they were initially designed for 8-10 tons of load are carrying modern vehicular load without any distress. Oarch bridges are one of the oldest types of bridges in existence and are popular for their aesthetic appeal and durability. Despite offering multiple benefits their use case became limited over time due to the difficult and timeconsuming construction process and requirement of skilled labour.0modern arch infrastructure, through lithely arch retains the core functionality of arch bridges, while eliminating all inconveniences. The lithely arch is based on the same principles of the conventional arch bridge and requires absolutely no maintenance once installed. The bridge is designed to have a service life of over 120 years, almost twice that of modern bridge solutions.

The lithely arch is India's only Precast, Unreinforced Bridge solution and is developed on the lines of the conventional stone-mason built arch bridges. 
Arch bridges are the most reliable and time tested solution for medium span ( $5 \mathrm{~m}$ to $20 \mathrm{~m}$ ) bridges. These bridges have been standing strong for centuries and while they were initially designed for 8-10 tons of load are carrying modern vehicular load without any distress.

Arch bridges are one of the oldest types of bridges in existence and are popular for their aesthetic appeal and durability. Despite offering multiple benefits their use case became limited over time due to the difficult and timeconsuming construction process and requirement of skilled labor.

Modern Arch Infrastructure, through lithely arch retains the core functionality of Arch bridges, while eliminating all inconveniences. The lithely arch is based on the same principles of the conventional arch bridge and requires absolutely no maintenance once installed. The bridge is designed to have a service life of over 120 years, almost twice that of modern bridge solutions

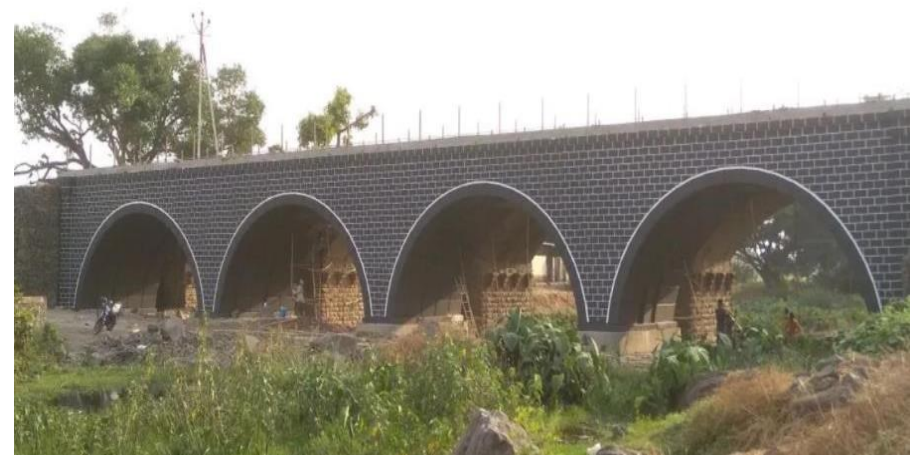

Figure No. 1 Lithely Arch Bridge

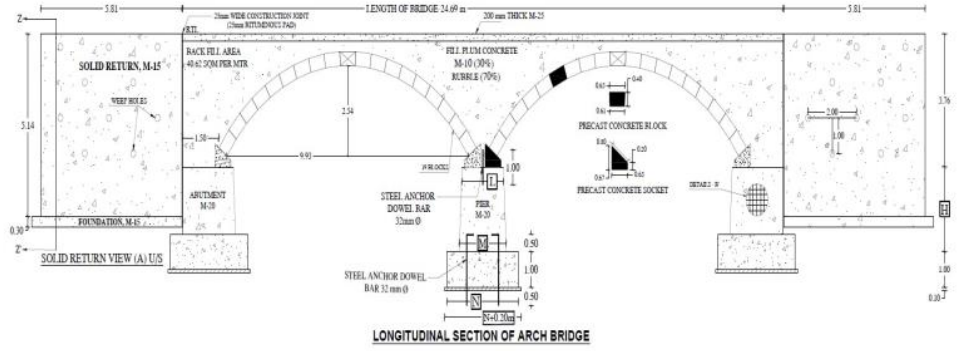

Figure No. 02. General Arrangement of Longitudinal Section of Arch Bridge

\section{ERECTION}

Footings must be prepared on each side of the structure. the attendant crane lifts each LITHELY ARCH strips and lowers it into position over the precast sockets laying a top the foundation / pier top the lithely strips arrive on site completely flat, laying upon flatbed transporters. The components includes the required number of arch strips based on the scope of the project, ready for lifting and placing in position precast concrete sockets act as the surface on which individual lithely arch strips are placed. These sockets are placed in line and level a top the piers, prior to the commencement of the erection activity. Once all strips have been poisoned and placed, block masonry spandrel walls are constructed up to the road top level. Spandrels do not carry ant traffic load but act as a permanent shuttering for the poured plum concrete acting as the back fill to the lithely arch strips .the bridge is then ready for roadway finishing and any railing protection that may require.

\section{Steps of Construction of Lithely Arch Bridge}

1) Steel mould for casting blocks

2) Sockets for resting arch

3) Concrete blocks in line and levels

4) Wire rope for lifting

5) Ready for screed concrete

6) Arch strips before screed and after screed

7) Lifting of strips

8) Arch strips arrive at site on trailer

9) Half lift of arch strip

10) Full lift of arch strips

11) Arches

12) Placed on sockets stabilized, no support required

13) Placing of arches for major bridge

14) Spandrel wall construction

15) Back filling procedure $60 \%$ rubble, $40 \%$ concrete

16) Proof load resting

17) Completed open for traffic 
International Journal of Engineering Applied Sciences and Technology, 2020

Vol. 5, Issue 4, ISSN No. 2455-2143, Pages 622-625

Published Online August 2020 in IJEAST (http://www.ijeast.com)

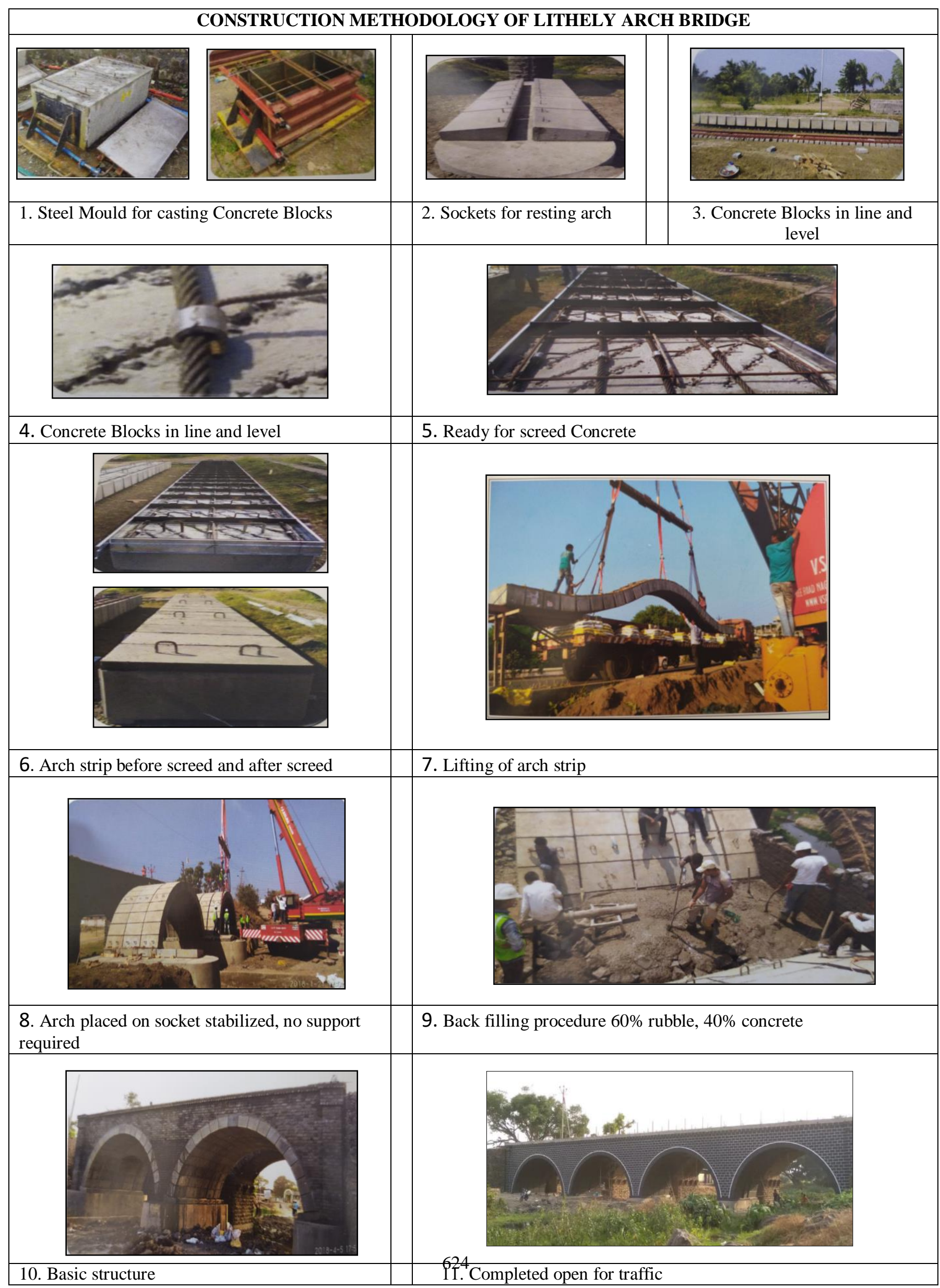


III.

\section{KEY BENEFITS OF LITHELY ARCH TECHNOLOGY}

1) Economic method of construction of arch bridge

2) As there is no use reinforcement in the method there are no chances of corrosion

3) No use of bearings and other attachments so there is no maintenance

4) Form-work is not needed in this method so this is the faster method of construction of arch bridges.

5) Load carrying capacity is high.

6) Less workers are required

7) Ensure life above 100 years

\section{CONCLUSION}

1. The lithely arch system requires no steel reinforced. As a compression structure, it is self -supporting by virtue of its own weight, without any external support.

2. With the absence of steel rebar content, the possibilities for internal correction, rebar expansion, and the resultant concrete cracking are eliminated.

3. These factors result in a substantially lower carbon footprint and energy consumption during the construction and overall life span of the bridge

4. Lithely Arch method is very useful for rehabilitation of old arch bridges in India.

5. Lithely Arch method is easy, fastest and economical method than other methods of construction of arch bridges.

\section{REFERENCE}

[1] Modern Arch Infrastructure, Nagpur

[2] IRC : 6-2016 ( Standard Specifications And Code Of Practice For Road Bridges)

[3] IRC: 24-2001(Standard Specifications And Code Of Practice For Road Bridges)

[4] Saurabh Vilas Joshi , G. N. Kanade,(2019) "Rehabilitation of arch bridges with lithely arch method", International Journal of Advance Research and Development.

[5] A. Long, Gupta, A., Mc Polin, D. Courtenay \& Cook, J. (2018). "Adapting The Flexiarch For Widening a Complex Arch Bridge". (c) Proceedings of ICE - Bridge Engineering, [1700007].

[6] A. Long, and Nanukuttan, S. (2016). "Arch Bridges Unlocking Their Potential". - Journal of Engineering and Computational Mechanics, (c) ICE Proceedings [1600018]. DOI: 10.1680/jencm.16.00018.
[7] Sykora M, Holicky M.(2010) "Probabilistic Model For Masonry Strength Of Existing Structures", Engineering Mechanics"

[8] Ali Ura, Seref Oruc. Adem Dogangu, Iskender Tuluk (2008), "Turkish Historical Arch Bridges And Their Deterioration's And Failures", International Journal of Engineering Failure Analysis15 (2008) @Elsevier Ltd. pp. 43-53.

[9] The Assessment of Highway bridges and structure departmental advice note BA16/97( AMD No 2,2001), Section 3- Assessment of masonry Arch Bridge by the Modification MEXE Method.

[10] Gilbert M, Hobbs B (1995) Impact Testing of Masonry Walls. 7 Proceedings of the British Masonry Society 97 100 UK. London.

[11] Choo, B.S. Contie, M.G. Gong, N.G. ,(1990) “'Analysis of Masonry Arch Bridges by a Finite Element Method", Developments in Structural Engineering Spon"

[12] Heyman, J, (1982)“The Masonry Arch' Ellis Horwood"

[13] Dr. C. Melbourne,(1990) "The assessment of masonry arch bridges".

[14] Hendry, A.W. Davies, S.R Royles, R,(1986) Load Test to Collapse on a Masonry Arch Bridge at Bargower, Strathclyde' TRRL Contractors Report 26,1986.

[15] Casas J.R. (2001). Reliability-based assessment o f existing arch bridges, Proc. 3rd International Arch Bridges Conference, Paris, 379-384.

[16] Boothby T. E. and Roberts B. J. (2001). Transverse behaviour of masonry arch bridges. Structural Engineer 79(9): 21-26.

[17] Hogg V. and Choo B. S. (1994). Serviceability requirements for masonry arch bridges. Research Project Report, 1-31. 